\title{
Orientation and Related Buoyancy Effects in Low-velocity Flow Boiling
}

\author{
Herman Merte, Jr., ${ }^{a}$ William W. Schultz, ${ }^{a}$ Quanyi Liu, ${ }^{b}$ \\ and Robert B. Keller ${ }^{a}$
}

${ }^{a}$ Department of Mechanical Engineering, University of Michigan, Ann Arbor, Michigan, USA

${ }^{b}$ Acrolab Ltd., Windsor, Ontario, Canada

\begin{abstract}
This work is an extension of experimental results reported previously, which might provide design guidance for approximating certain aspects of the flow boiling process in microgravity but taking place in Earth gravity. In that research the buoyancy effects on the bubble dynamics were minimized by the imposition of a liquid velocity parallel to a flat heater surface in the inverted horizontal position, or nearly horizontal (within $\pm 5^{\circ}$ ), thus holding the heated liquid and vapor formed close to the heater surface. For the fluid used, liquid velocities in the range $U=5-10 \mathrm{~cm} / \mathrm{s}$ were judged to be critical for changes in the behavior of the flow boiling process. Using the hydraulic diameter of the rectangular duct used, with the heater surface embedded in one side, this velocity range gives rise to flow Reynolds numbers on the order of 4400-8800. It was subsequently judged to be of interest to extend the range of orientation of the flat heater surface relative to gravity to the full circular range of $0-360^{\circ}$, in increments of $45^{\circ}$, and the results of this work are presented here. A solid massive copper heater with a gold-plated boiling heat transfer surface $19 \times 38 \mathrm{~mm}$ in size, previously used for critical heat flux measurements with boiling, provided a near-uniform surface temperature. Only steady measurements of heat flux and surface temperature were possible with the copper heater. R-113 was the fluid used; the velocity was varied over the interval of $4-28 \mathrm{~cm} / \mathrm{s}$; bulk liquid subcooling was varied over $5-11^{\circ} \mathrm{C}$; and heat flux varied over $0-10 \mathrm{w} / \mathrm{cm}^{2}$.
\end{abstract}

Key words: low-velocity flow boiling; approximations to microgravity boiling; orientation of flat heater surfaces varied $0-360^{\circ}$

\section{Introduction}

Nucleate boiling is a complex phenomenon influenced by many elements and is generally desired because of its high effectiveness for heat transfer rates relative to its driving force, the temperature difference. Identifying and isolating the various forces and mechanisms that influence the heat transfer provide great challenges and hence make the process difficult to model. Among the forces are buoyancy or its lack in extended flights in space.

Address for correspondence: Herman Merte, Jr., Department of Mechanical Engineering, 2260 G.G. Brown Bldg., University of Michigan, Ann Arbor, MI 48109-2125. Voice: 734-647-9475; fax: 734-647-3170. merte@umich.edu
The lack of adequate understanding of the behavior of flow boiling in microgravity during the development of the space shuttle in the 1970s required the conservative use of singlephase forced convection heat transfer in transporting the heat generated in the shuttle interior to the exterior, for removal by thermal radiation. The penalties associated with this approach were the excess mass and pumping power required. We hope that the necessary technology for the effective and reliable use of boiling will be available when the next generation of space vehicles undergoes development. The beginning of such research in preparation for long-term microgravity experiments has taken place by varying the component of Earthgravity buoyancy normal to flat heater surfaces 


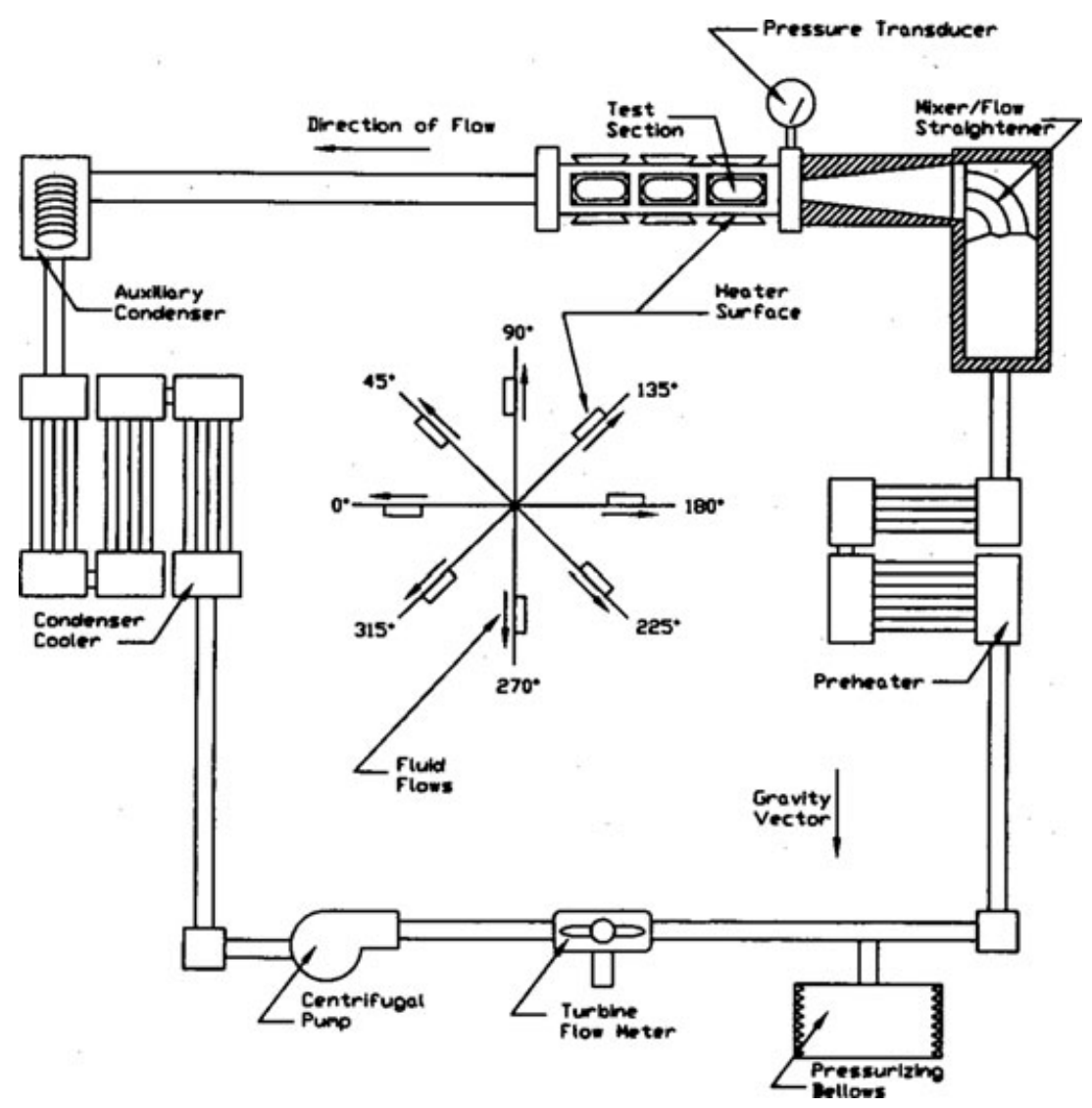

Figure 1. Forced convection flow loop.

by rotation of the flow loop hardware. ${ }^{1,2}$ Short-term microgravity experiments have also taken place using aircraft flying parabolic trajectories. ${ }^{3}$

The experimental results by Merte et al. ${ }^{2}$ were conducted with relatively low velocities, with the view of conservation of power in potential space applications, together with concentration on orientations that provide the largest reductions in buoyancy parallel to the heater surface, varying a maximum of + and $-5^{\circ}$ from facing horizontal downward. It was subsequently judged to be of potential interest to extend the range of orientation of the flat heater surface (and flow loop) relative to gravity to the full circular range of $0-360^{\circ}$, in increments of $45^{\circ}$ for relatively low fluid flow velocities. The results of this research are provided here.

\section{Description of Experimental Hardware}

A schematic of the forced convection boiling loop is given in Figure 1. The loop is mounted on an axis near its center of gravity such that it can be rotated a full $360^{\circ}$ while in operation in order to obtain the various heater surface orientations. Also shown is the correspondence between the vertical gravity vector and the fluid flow direction over the flat heater surface, beginning with $0^{\circ}$ for horizontal facing upward. The loop consists of five basic components: the test section, the condenser-cooler, the flow system, the pressure control system, and the preheater system. Degassed R-113 was used as the test fluid. The sufficiency of the degassing process was demonstrated by comparing the measured vapor pressure curve with published 


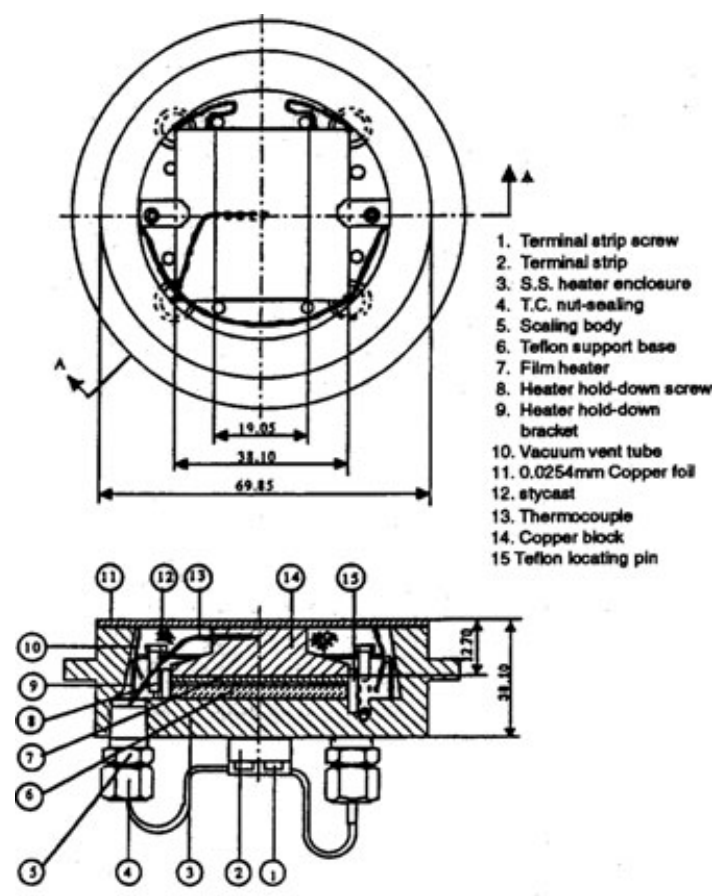

Section A-A

Figure 2. Encapsulated copper heater A.

saturation properties over the domain of interest.

The test section provides a rectangular flow cross section $10.80 \mathrm{~cm}$ wide by $1.27 \mathrm{~cm}$ high by $35.56 \mathrm{~cm}$ long $(4.25 \times 0.50 \times 14.0 \mathrm{in})$, capable of accommodating three heater surfaces on each side. Viewing windows made of optical-grade quartz permit a transverse view of the boiling process on the flat heaters. The condenser-cooler system condenses R-113 vapor leaving the test section and subcools the liquid sufficiently to avoid cavitations at the pump inlet. The pressure control system actively maintains the pressure in the flow loop to within $\pm 0.34 \mathrm{kPa}( \pm 0.05 \mathrm{psi})$ and consists of four main components: a bellows, valves, electronic control circuits, and a pressure transducer. The 17.78-cm (7.0 in)-diameter stainless steel bellows separates the test fluid from the air in the chamber surrounding the bellows. Air is continuously admitted to the chamber through a manually adjusted needle valve and is vented from the chamber through an electronically controlled proportional valve. The

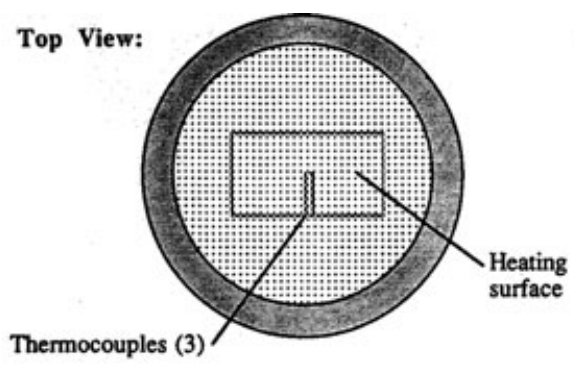

Side View (cross section):

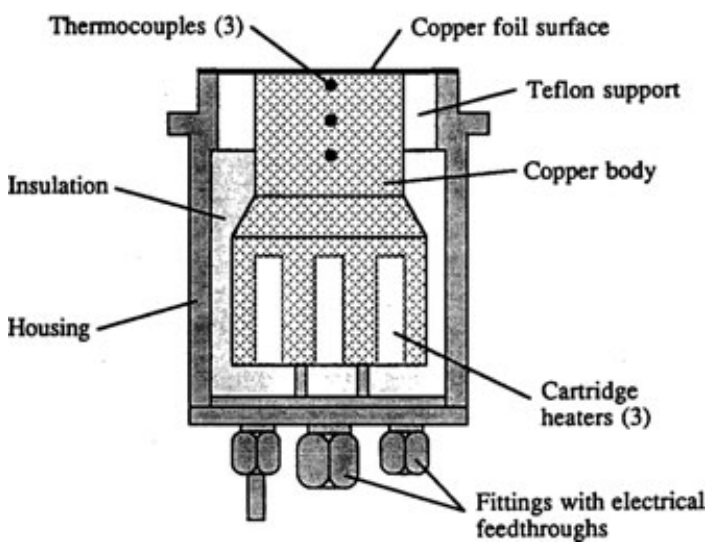

Figure 3. High-heat flux copper heater B.

preheater is used to raise the temperature of the R-113 to the desired level at the inlet to the test section.

The heater surfaces installed in the test section were of dimensions generally much larger than the bubbles growing on them in order that they would be more representative of boiling surfaces encountered in engineering applications. These were rectangular, $1.905 \times 3.81 \mathrm{~cm}$ $(0.75 \times 1.50 \mathrm{in})$, with the smaller length in the flow direction. Two different copper heaters were used for the results to be discussed here. Heater A in Figure 2 consists of a copper block with a film heater on the underside and embedded in an electrical encapsulating potting compound. This could provide a maximum estimated heat flux at the boiling surface of $15 \mathrm{w} / \mathrm{cm}^{2}$. Heater B in Figure 3 is also copper, with three cartridge heaters in the base, and could provide a maximum estimated heat flux at the boiling surface of $80 \mathrm{w} / \mathrm{cm}^{2}$. A smooth 


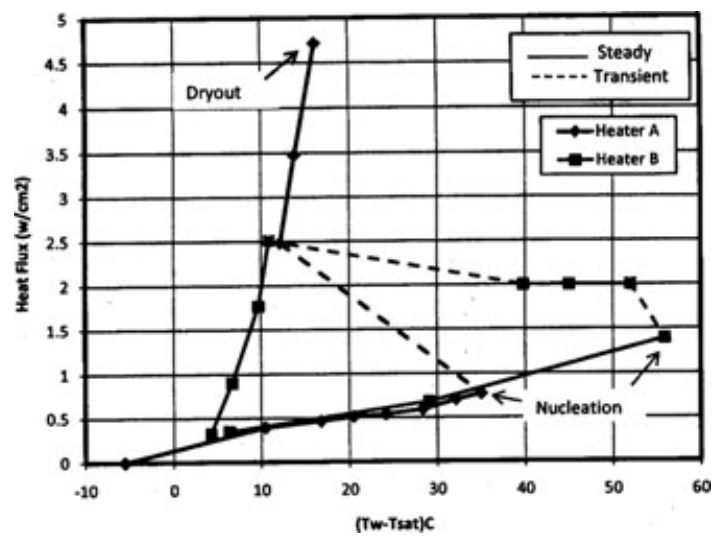

Figure 4. Reproducibility comparison between copper heaters A and B. Velocity $=8 \mathrm{~cm} / \mathrm{s}$; subcooling $=5^{\circ} \mathrm{C}$; orientation $=180^{\circ}$.

copper foil $0.0254 \mathrm{~mm}$ (0.001 in) thick was soldered to each copper block and to the stainless steel holders to eliminate the artificial boiling that otherwise would result at the heater edge. The copper foils were sputtered with gold, approximately $1000 \AA$ thick, to provide identical surface-liquid energy combinations. Chromelconstantan thermocouples with a bead of $0.64-\mathrm{mm}(0.025 \mathrm{in})$ diameter were inserted into $0.76-\mathrm{mm}$ (0.030 in)-diameter holes in the copper heaters to estimate the temperature of the copper foil. The hole for the thermocouple was then filled with a thermally conducting copper compound. The tip of the upper thermocouple was about $0.76 \mathrm{~mm}$ (0.030 in) from the gold-sputtered copper foil. The measured metal heater surface temperature had an estimated error of $\pm 0.1^{\circ} \mathrm{C}$. The copper heater $\mathrm{A}$ of Figure 2 reached new steady temperatures within 5-10 min after changes in power level, whereas copper heater B in Figure 3 required 30-45 min to reach the new steady temperature for each change in power level. Because of uncertainties in the anticipated heat flux levels to be used, the copper heater B in Figure 3 was selected to produce the results to be presented here. This is the same heater used for the critical heat flux boiling studies of Brusstar and Merte, ${ }^{1}$ whereas copper heater A in Figure 2 was used in the studies of Merte et al., ${ }^{2}$ cited earlier.

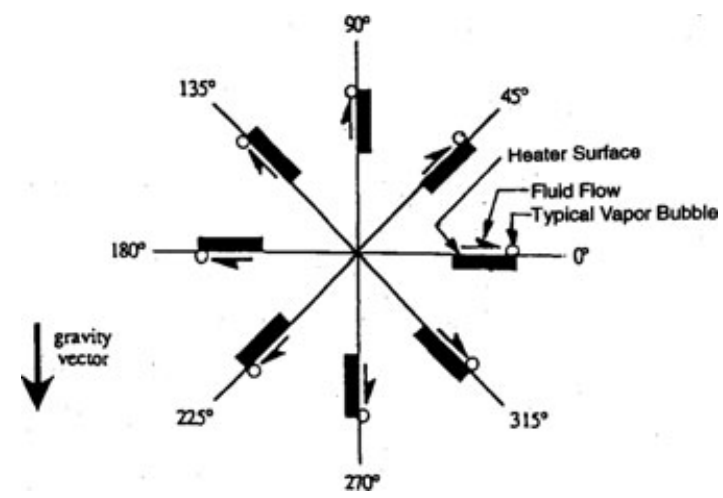

Figure 5. Orientation definitions for flat forced convection boiling heater surface in a gravity field.

Considerable efforts were expended to confirm that reproducible results were obtained with both heaters for identical conditions, with one of the examples shown in Figure 4. In general, the solid lines and the corresponding data points here and in the results section represent steady conditions, whereas the dashed lines and intermediate data points for a given test represent slowly changing conditions after nucleation, as the transient boiling process responds to the slow change in the heater surface temperature (due to the large heat capacity of copper heater B in Fig. 3). Once nucleation took place, the changes in heat flux between the intervening steady conditions were a result of the changes in calibrated heat losses to the surroundings, and at times to changes in power input to the heaters. When steady nucleate boiling had been attained, except for some of the data shown in Figures 4, 6, and 7, the heat flux was then increased in steps to some maximum value and then reduced in steps until steady nucleate boiling ceased. Each value represented by a symbol on the solid line in the plots is a steady value, requiring 30-45 min. It was consistently observed that once a steady-state was reached with nucleate boiling, the values relating heat flux and heater surface superheat were quite reproducible. It was only the heater surface superheat at the initial nucleation point that differed to some extent. Further details are given in Liu et al. ${ }^{4}$ Each experimental condition of a given fluid velocity, liquid subcooling, 


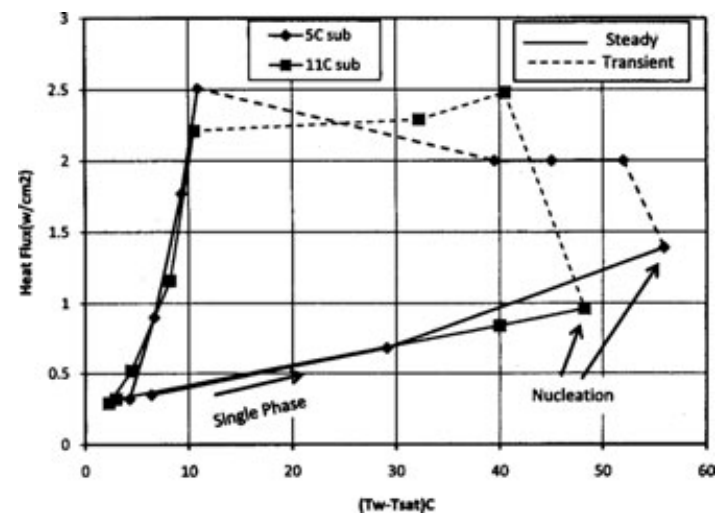

Figure 6. Effect on heat transfer of subcooling of $5^{\circ} \mathrm{C}$ and $11^{\circ} \mathrm{C}$ with lower velocity $=8 \mathrm{~cm} / \mathrm{s}$ and orientation $=180^{\circ}$.

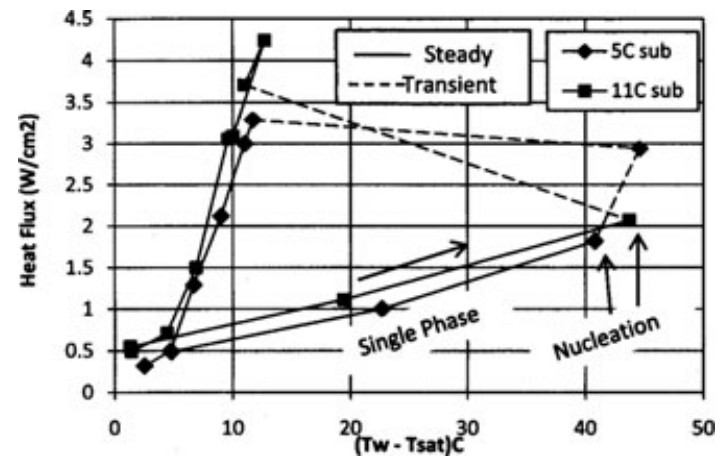

Figure 7. Effect on heat transfer of subcooling of $5^{\circ} \mathrm{C}$ and $11^{\circ} \mathrm{C}$ with higher velocity $=18 \mathrm{~cm} / \mathrm{s}$ and orientation $=180^{\circ}$.

and heater surface orientation began with zero power input and progressed to nucleation via the single-phase steady forced convection domains. The large heat capacity of the copper heater $\mathrm{B}$ resulted in the average test time for each experimental condition of about 8-10 h. The test matrix covered is given in Table 1 . Some additional parameters not covered here are given in Merte et $_{a l}{ }^{2}$

\section{Results}

The effects of variations in relatively low fluid velocities and subcoolings with flow boiling on flat surfaces are better understood when the configurations can be visualized. This is shown in Figure 5 for the specific orientations used here. For angles between $0^{\circ}$ and $180^{\circ}$ on the upper half, buoyancy acts in the same direction as the fluid velocity on the heated liquid and vapor bubbles and counter to the fluid velocity for angles between $180^{\circ}$ and $0^{\circ}$ on the lower half. Also, for angles between $90^{\circ}$ and $270^{\circ}$ on the left half of Figure 5, buoyancy acts to hold the heated liquid and vapor bubbles on the heater surface, whereas for angles between $270^{\circ}$ and $90^{\circ}$ on right half, buoyancy tends to act to remove the heated liquid and vapor bubbles from the heater surface. The net effects of these with the imposed fluid flow results in complex heat transfer phenomena. The higher the fluid velocity, the less significant will buoyancy be on the overall process. Also, for long-term space applications, higher pumping power associated with increased fluid velocities leads to optimization considerations.

Figures 6 and 7 demonstrate the effects on the heat transfer with subcoolings of $5^{\circ} \mathrm{C}$ and $11^{\circ} \mathrm{C}$ for low and medium velocities of 8 and $18 \mathrm{~cm} / \mathrm{s}$, respectively, for the downward-facing orientation of $180^{\circ}$. This holds the heated liquid and vapor bubbles against the heater surface. The effect of the higher subcooling is more evident at the higher velocity in Figure 7, for both the single-phase and the nucleate boiling domain, as might be expected. This finding is consistent with the results of Merte et al. ${ }^{2}$ for both the transient thin-film heater and the encapsulated copper heater A. Several additional elements between Figures 6 and 7 are noteworthy because the heater surfaces and working fluid in both are the same, including not only the substrate materials and surface coating but also the microscopic geometrical description of the surface, which tends to influence the heater superheat at which the initial vapor nucleation takes place, as well as the number and density variations of the resulting steady active nucleation sites. Practical considerations did not permit measurement of microscopic geometrical details of the heater surface. The heater surface superheat at the initial nucleation is lower with the higher liquid velocity in Figure 7, than in Figure 6, whereas the corresponding heat flux is considerably higher. 
TABLE 1. Copper Heater B test Matrix

\begin{tabular}{|c|c|c|c|c|c|c|c|c|c|}
\hline \multirow[b]{2}{*}{ Velocity $(\mathrm{cm} / \mathrm{s})$} & \multirow[b]{2}{*}{ Subcooling $\left({ }^{\circ} \mathrm{C}\right)$} & \multicolumn{8}{|c|}{ Orientation $\left(^{\circ}\right)$} \\
\hline & & 0 & 45 & 90 & 135 & 180 & 225 & 270 & 315 \\
\hline 4 & 5 & & & & & & & & \\
\hline 4 & 11 & & & & & & & $\times$ & \\
\hline 8 & 5 & $x$ & & $x$ & & $\times$ & & $\times$ & \\
\hline 8 & 11 & $x$ & $x$ & $x$ & $x$ & $\times$ & $\times$ & $x$ & $x$ \\
\hline 18 & 5 & $x$ & & $\times$ & & $\times$ & & $\times$ & \\
\hline 18 & 11 & $x$ & $x$ & $x$ & $\times$ & $\times$ & $\times$ & $x$ & $\times$ \\
\hline 28 & 5 & & & & & & & & \\
\hline 28 & 11 & & & & & & & $x$ & \\
\hline
\end{tabular}

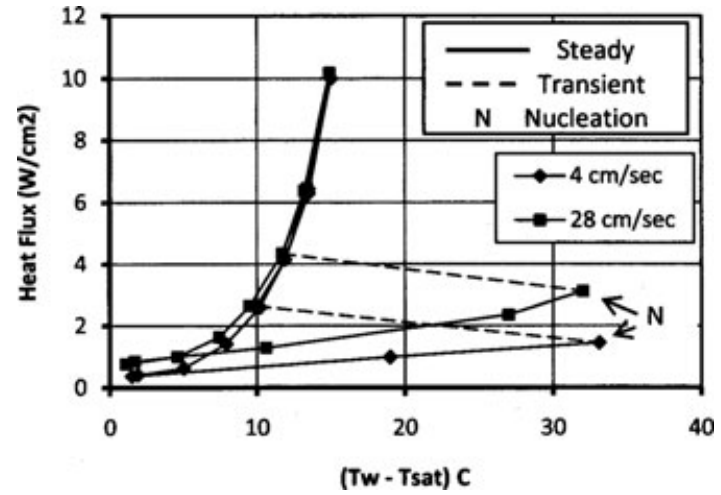

Figure 8. Effect on heat transfer of maximum velocity change $4 \mathrm{~cm} / \mathrm{s}$ to $28 \mathrm{~cm} / \mathrm{s}$ for higher subcooling $=11^{\circ} \mathrm{C}$ and maximum adverse orientation buoyancy $=270^{\circ}$.

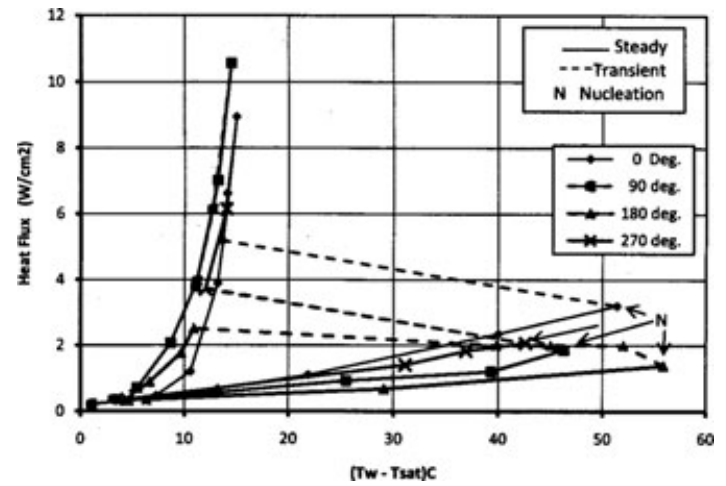

Figure 9. Effect on heat transfer of the four principal $90^{\circ}$ orientation changes for velocity $=8 \mathrm{~cm} / \mathrm{s}$ and subcooling $=5^{\circ} \mathrm{C}$.

Figure 8 shows the effect of the maximum velocity change $4 \mathrm{~cm} / \mathrm{s}$ to $28 \mathrm{~cm} / \mathrm{s}$ for the higher subcooling $=11^{\circ} \mathrm{C}$ with the maximum adverse orientation buoyancy $=270^{\circ}$. The downward

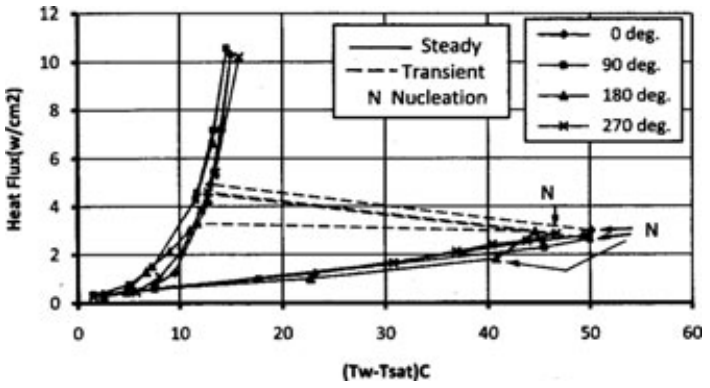

Figure 10. Effect on heat transfer of the four principle $90^{\circ}$ orientation changes for velocity $=18 \mathrm{~cm} / \mathrm{s}$ and subcooling $=5^{\circ} \mathrm{C}$.

fluid flow counters the buoyancy of the heated liquid and vapor bubbles. In Figure 8 the relatively wide range of liquid velocity with the adverse buoyancy of $270^{\circ}$ has little effect on the heat flux above $6 \mathrm{w} / \mathrm{cm}^{2}$. It is speculated that the adverse buoyancy and the liquid velocity gradient at the heater surface moves the vapor generated away from the heater. This supposition is reinforced by comparing the heat flux levels at a heater surface superheat of $10^{\circ} \mathrm{C}$ between Figures 7 and 8. For the same liquid subcooling the horizontal downward-facing heater orientation of Figure 7 produces a higher heat flux, most likely because of the more effective "scrubbing" of the superheated boundary layer by the vapor bubbles. We will present the comparisons of this effect on the heat transfer for a variety of orientations.

In Figures 9-12, the effects on the heat transfer of the four principal $90^{\circ}$ orientation changes in Figure 5 are given, for subcooling $=5^{\circ} \mathrm{C}$ in 


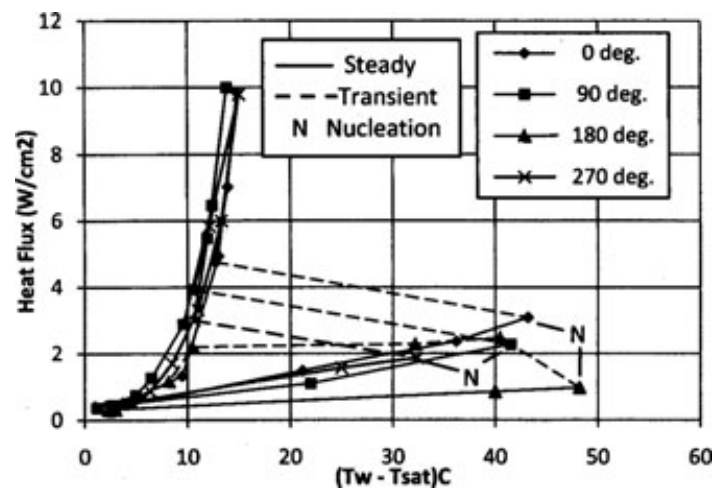

Figure 11. Effect on heat transfer of the four principal $90^{\circ}$ orientation changes for velocity $=8 \mathrm{~cm} / \mathrm{s}$ and subcooling $=11^{\circ} \mathrm{C}$.

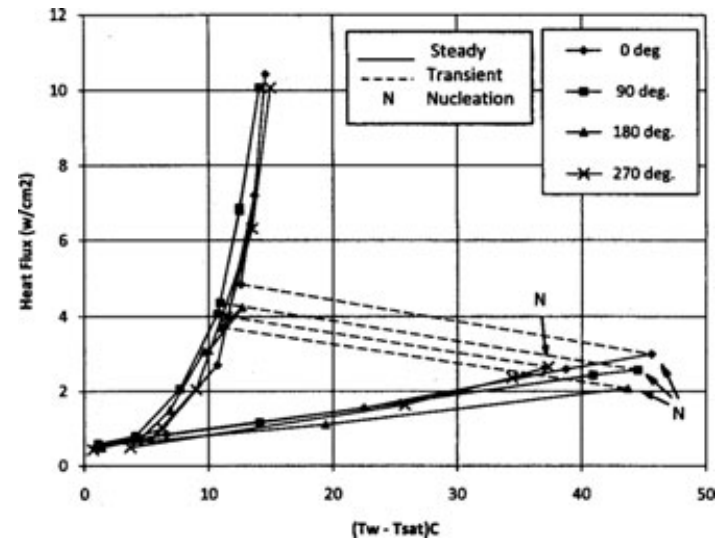

Figure 12. Effect on heat transfer of the four principal $90^{\circ}$ orientation changes for velocity $=18 \mathrm{~cm} / \mathrm{s}$ and subcooling $=11^{\circ} \mathrm{C}$.

Figures 9 and 10 and subcooling $=11^{\circ} \mathrm{C}$ in Figures 11 and 12, and for velocity $=8 \mathrm{~cm} / \mathrm{s}$ in Figures 9 and 11 and velocity $=18 \mathrm{~cm} / \mathrm{s}$ in Figures 10 and 12. On comparing Figures 9 and 10, with the same low subcooling, the orientation changes have less effect with the higher velocity in Figure 10, on both the single-phase and boiling heat transfer. At the lower velocity the vapor bubbles rising away from the heater surface with the $0^{\circ}$ orientation are less effective in disturbing the boundary layer heat transfer than at the $180^{\circ}$ orientation. For the singlephase heat transfer, comparing the effect of increasing the subcooling for the same velocities, as with Figures 9 and 11, and with Figures 10 and 12, the heat flux is increased, as expected.

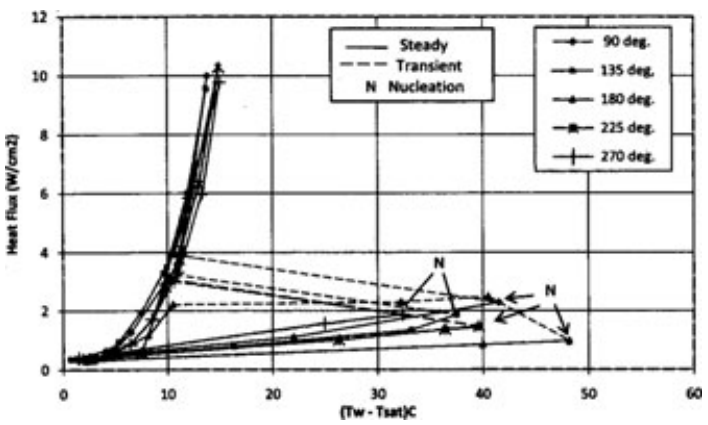

Figure 13. Effect on heat transfer of the four $45^{\circ}$ orientation changes $\left(90^{\circ}, 135^{\circ}, 180^{\circ}, 225^{\circ}, 270^{\circ}\right)$ for velocity $=8 \mathrm{~cm} / \mathrm{s}$ and subcooling $=11^{\circ} \mathrm{C}$.

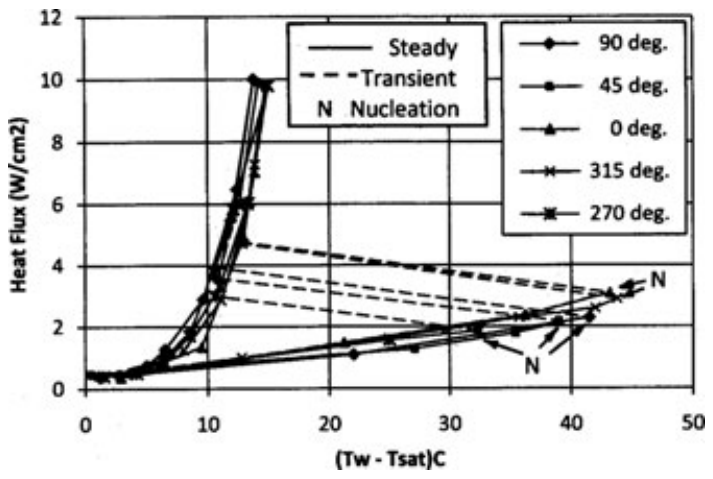

Figure 14. Effect on heat transfer of the four $45^{\circ}$ orientation changes $\left(90^{\circ}, 45^{\circ}, 0^{\circ}, 315^{\circ}, 270^{\circ}\right)$ for velocity $=8 \mathrm{~cm} / \mathrm{s}$ and subcooling $=11^{\circ} \mathrm{C}$.

In Figures 9-12, the change in the heat flux with the four principal orientation changes, for a given heater surface superheat in the nucleate boiling domain, is on the order of $2-4 \mathrm{w} / \mathrm{cm}^{2}$. In Figure 9, for example, this translates to changes in heat flux of $40 \%-50 \%$, depending on the level of the heat flux. It was then speculated as to whether intermediate orientations between the four principal $90^{\circ}$ orientations might produce dramatically different results. To determine this possibility, further experimentation took place with $45^{\circ}$ orientation changes over the entire interval of $0^{\circ}$ $360^{\circ}$. As can be seen in the test matrix in Table 1, this was conducted only for one liquid subcooling $=11^{\circ} \mathrm{C}$ and two fluid velocities of 8 and $18 \mathrm{~cm} / \mathrm{s}$. The results are presented in Figures 13-16. 


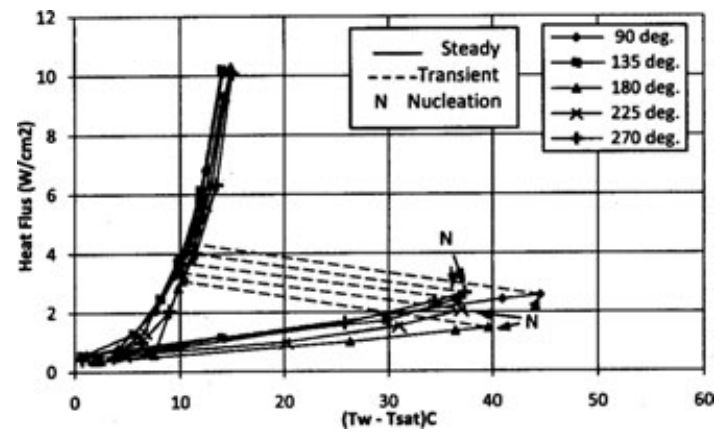

Figure 15. Effect on heat transfer of the four $45^{\circ}$ orientation changes $\left(90^{\circ}, 135^{\circ}, 180^{\circ}, 225^{\circ}, 270^{\circ}\right)$ for velocity $=18 \mathrm{~cm} / \mathrm{s}$ and subcooling $=11^{\circ} \mathrm{C}$.

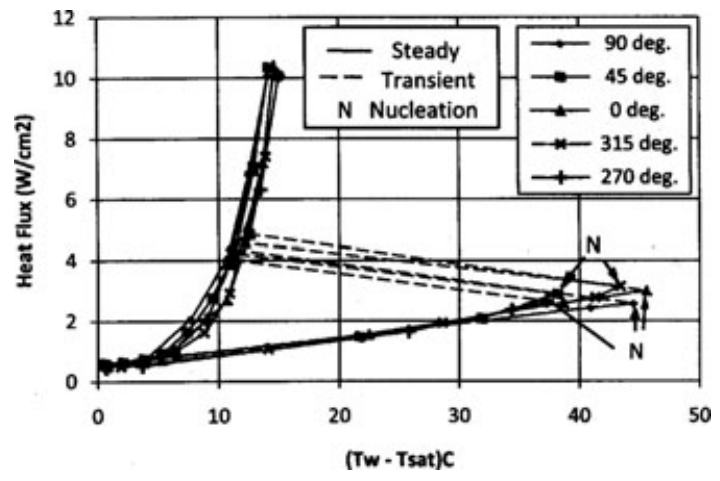

Figure 16. Effect on heat transfer of the four $45^{\circ}$ orientation changes $\left(90^{\circ}, 45^{\circ}, 0^{\circ}, 315^{\circ}, 270^{\circ}\right)$ for velocity $=18 \mathrm{~cm} / \mathrm{s}$ and subcooling $=11^{\circ} \mathrm{C}$.

To minimize the confusion associated with including too many data points on each plot, both velocity series of $360^{\circ}$ were divided into two $180^{\circ}$ intervals. Viewing the orientation definitions in Figure 5, the division within each velocity was made depending on whether the buoyancy tended to move the vapor bubbles into or away from the heater surface. Thus Figures 13 and 14, for the velocity $=8 \mathrm{~cm} / \mathrm{s}$ and subcooling $=11^{\circ} \mathrm{C}$, apply to the four $45^{\circ}$ orientation intervals between $90^{\circ}, 135^{\circ}, 180^{\circ}, 225^{\circ}$, and $270^{\circ}$ and between $90^{\circ}, 45^{\circ}, 0^{\circ}, 315^{\circ}$, and $270^{\circ}$, respectively. For completeness, the orientations of $90^{\circ}$ and $270^{\circ}$ are common to both Figures 13 and 14 . The same four $45^{\circ}$ orientation interval divisions are given in Figures 15 and 16 , for the velocity $=18 \mathrm{~cm} / \mathrm{s}$ and subcooling $=11^{\circ} \mathrm{C}$.
In comparing the influence of the orientation changes on the single-phase heat transfer in Figures 13-16, the least influence occurs for the highest velocity of $18 \mathrm{~cm} / \mathrm{s}$ in Figure 16, where the heater surface is facing upward, whereas maximum influence occurs for the lower velocity of $8 \mathrm{~cm} / \mathrm{s}$ in Figure 13, where the heater surface is facing downward. The maximum influence of the orientation changes on the nucleate boiling heat flux also takes place with the heater facing downward, varying 30\%-40\% at the lower velocity in Figure 13, and 30\% facing upward in Figure 14, compared with the corresponding changes of $25 \%-30 \%$ in Figure 15 and $20 \%-30 \%$ in Figure 16. One must use care in extrapolating these effects to higher levels of heat flux because the critical heat flux phenomena is strongly influenced by the heater surface orientation, as was demonstrated in the work of Brusstar and Merte. ${ }^{1}$

\section{Conclusion}

It has been demonstrated that variations of the orientation of the flat flow boiling heater surfaces in a gravity field at relatively low velocities can produce changes of $20 \%-50 \%$ in the heat flux, depending on the specific circumstances, and indicate that buoyancy, or its absence, can have significant influences.

\section{Acknowledgment}

The research presented here was conducted with NASA support under Grant NAG3-1900.

\section{Conflicts of Interest}

The authors declare no conflicts of interest.

\section{References}

1. Brusstar, M.J. \& H. Merte, Jr. 1994. The effects of buoyancy on the critical heat flux in forced convection. AIAA 7. Thermophys. Heat Transfer 8: 322-328. 
2. Merte, H. Jr., J. Park, W.W. Schultz \& R.B. Keller. 2002. Criteria for approximating certain microgravity flow boiling characteristics in earth gravity. Ann. N. Y. Acad. Sci. 974: 481-503.

3. Ohta, H. 2002. Heat transfer mechanisms in microgravity flow boiling. Ann. N. Y. Acad. Sci. 974: 463-480.
4. Liu, Q., H. Merte, Jr., H.S. Lee \& R.B. Keller. 1999. Boiling incipience in subcooled forced convection with a highly-wetting fluid and variable orientation. NASA Grant NAG-3-1900, Report No. UM-MEAM-99-09, Department of and Applied Mechanics, University of Michigan, Ann Arbor, MI. 